\title{
Synonymy in Jordanian Arabic
}

\author{
Omar Ibrahim Salameh Alomoush \\ English Department, Tafila Technical University, Tafila 66110, Jordan \\ E-mail: alomoushomar@ttu.edu.jo
}

Doi:10.7575/aiac.alls.v.7n.3p.243

Received: 23/02/2016

URL: http://dx.doi.org/10.7575/aiac.alls.v.7n.3p.243

Accepted: 11/04/2016

\begin{abstract}
This paper is devoted to the investigation of synonymy in Jordanian Arabic. It has been assumed that synonymy in Jordanian Arabic has partial rather than complete synonymy. This means that the abundance of Jordanian Arabic in synonyms can be attributed to a number of explanations, namely dialectical variations, the speaker's attitude, and origin of words. The data for this study come from two main sources: written and spoken material. In accordance with the established literature on the semantics of synonymy, we have classified the corpus of the study on the basis of these parameters. The main findings reveal that total synonymy is hard to find in Jordanian Arabic, supporting the argument of many linguistic studies for the existence of partial rather than total synonymy in a language.
\end{abstract}

Keywords: dialectical variations, evaluative meaning, origin of words, semantics, synonyms

\section{Introduction}

Issues in semantic relations (e.g. synonymy, antonymy, hyponymy, polysemy, homonymy, etc.) are seen as fundamentally important from the perspective of lexical semantics. The current study will focus on synonymy in Jordanian Arabic, which has not been given much attention by semanticists. In contrast, the uses of semantically-related words such as synonymy in Classical Arabic and in the Quran are given much attention by Arab linguists, as the language variety of the Quran, the Holy Book of Islam, is widely spread throughout the Arab World (Al-Omari \& AbuMelhim, 2014; Llyas, 2014; Omar, 2000). This paper will first review the literature on the semantics of synonymy. In the subsequent section, we will briefly look at the language situation in Jordan. In the remaining sections, we will highlight the method used to collect the data, the main findings of the study and conclusions.

Expressions can be synonymous and have semantic relationships with other expressions in a language. The study of synonyms in any given language can contribute to the understanding of word meaning. Why is synonymy important in studying the semantics of a language? One way to answer this question is to understand what synonymy means. Even though synonymy means 'semantic equivalence', complete synonymy can only occur when words have exactly the same meaning in all contexts. On the one hand, some linguists such as Bloomfield (1935: 145) argue that 'there are no actual synonyms'. That is why Palmer (1981) argues that absolute synonymy does not exist. This means that partial synonymy is more acceptable where synonyms are not interchangeable in all contexts. On the other hand, other linguists (Lyons, 1969 and 1981; Cruse, 1986 and 2000) never deny the existence of synonymy in a language, but they differ on what is to be considered synonymy. According to Cruse (1986), total synonymy occurs when two lexical items would have identical contextual relations. According to Lyons (1981: 50, 51), 'two or more expressions are absolutely synonymous if, and only if, they satisfy three conditions':

1. synonyms are fully synonymous if, and only if, all their meanings are identical;

2. synonyms are totally synonymous if, and only if, they are synonymous in all contexts;

3. synonyms are completely synonymous if, and only if, they are identical on all

(relevant) dimensions of meaning.

Lobner (2002) also argues that absolute synonymy is non-existent in lexemes. Those who undertake to argue for the existence of partial synonymy, as articulated by Lyons (1981) and later by Cruse (1986), (who argues that Lyons' distinction of near-synonymy and partial synonymy is established needlessly), provide the defining characteristics of synonymy ${ }^{1}$.

Palmer (1981) notes that synonyms are characterised by different distributions according to a set of parameters. First, synonyms might belong to different language varieties, as in the case of British English pavement and American English sidewalk, both of which are synonyms for those who are familiar with the two language varieties. Second, lexical items might belong to different registers and styles; for example, children is more formal than kids and big is more commonly used in speaking than large. Third, even though words might have the same literal meaning (denotation), they might have different connotations (i.e. synonyms might betray the speaker's emotive attitude).

\footnotetext{
${ }^{1}$ Cruse (1986) discerns three main degrees of synonymy: absolute, propositional and near-synonymy.
} 
Elhassan (2001) adds origin of words as a distinguishing factor, as shown in the words borrowed from English into Arabic such as raadyuu, 'radio', kumpyutar, 'computer', laabaat, 'laboratories', and fainalaat, 'final exams'2.

The current study is concerned with synonymy, here defined as a relation of similarity in meaning between single words: for example, formal English policemen and informal English cops are synonymous adjectives. This paper attempts to investigate the semantics of synonymy in Jordanian Arabic, arguing that it is very rare to find absolute synonyms in Jordanian Arabic based on dialectical differences, evaluative and emotive meaning, or origin of words. Since it is very hard to find perfect synonymy, we will discuss synonymy in accordance with sub-dialects of Jordanian Arabic, connotative associations and origin of words.

\section{The language situation in Jordan}

The language situation in Jordan is characterised by the dominance of one national language, namely Arabic. Since three main varieties of Arabic co-exist in Jordan, we can argue for the existence of multiglossia, contradicting Ferguson (1959), who argues that there is a diglossic situation in the Arab world. In addition to Classical Arabic, the language variety of the Quran, Modern Standard Arabic and Jordanian Arabic are all used in Jordanian social settings where each one has its own distinct uses. Classical Arabic, which is also called Alfusha, the eloquent language, is mainly used in religious domains and settings and reflects the history of Arab and Islamic culture. As far as Modern Standard Arabic is concerned, it is the language variety used in primary and secondary schooling and is significantly employed in formal situations. In contrast, informality is closely linked to Jordanian Arabic insofar as it is mainly used in daily verbal interactions, particularly in informal situations.

Jordanian Arabic also consists of a range of sub-dialects. This means that the language variety spoken across the country's regions varies considerably. In northern Jordan, Falahi Dialect is commonly used in Irbid, Jerash and Ajloun, while, in the western part of the country, Salt Dialect is frequently used among the people of Balqa governorate. In central Jordan, Urban Dialect is significantly used in Amman city and Zarka city, while Bani Hassan Dialect is common among the members of the Bani Hassan tribe mainly living in Zarqa, Jerash and Mafraq governorates. In southern Jordan, Karak Dialect is common among the residents of Karak governorate, while Tafila Dialect is mainly used among the residents of Tafila governorate. In the eastern part of the country, Bedouin Dialect is the dominant medium of communication.

Even though the use of English is not stipulated in the Jordanian Constitution (1952), it plays an essential part in Jordan's educational policy due to its role in promoting the country's economic growth, scientific and industrial advancement, progress and communication with the outside world. English was first introduced during the British Mandate in 1921, the date which witnessed the establishment of the Emirate of Jordan. After the declaration of Jordan's independence from Britain in 1946, the Hashemite Kingdom of Jordan has taken further steps to promote the use of English in many social settings such as primary and secondary schools, universities and the linguistic landscape. Today, English is taught as an obligatory course at schools from the first grade. This has led to the infiltration of English loanwords into Arabic, one of the main sources of synonymy in Jordanian Arabic, as will be discussed in detail in the subsequent sections.

Other foreign languages (e.g. French and Turkish) are less common, but are used by people who have cultural and commercial interests with the countries concerned. In light of the international status of French, the education curriculum of many private schools in the capital city include French as one of its components. During the Ottoman rule, many words of Turkish origin infiltrated into the lexicon of the Arabic language and are still used in spoken Arabic.

\section{The corpus used in the study}

The corpus used in this study consists of spoken and written data. The former source is wholly dependent on the researcher's observation of the synonyms used in Jordanian social settings and different domains of use. In everyday life activities, Jordanians engage in conversations and deliver speeches, using a wide range of synonyms closely linked to different sub-dialects of Jordanian Arabic. In addition, it was found that the synonyms collected might express different connotations and might be associated with different foreign-origin sources. The latter resource is not only based on written material such as monolingual and multilingual signs in the linguistic landscape of urban and rural Jordan, but it is also dependent on other written resources that allow for longer segments of text found in daily newspapers.

In order to examine the parameters controlling the construction of synonymy in Jordanian Arabic, the synonyms collected have been classified based on certain sub-dialects of Jordanian Arabic, (as discussed in the preceding section), connotative meaning and origin of words. Not only is the current research dependent on our knowledge of synonymy in Jordanian Arabic, but we also communicated with people using these words to identify the speaker's intent, particularly the words expressing the speaker's emotive attitude.

\section{Results and discussion}

This section presents the primary results of the current study and discusses the results according to a set of parameters. These include dialectical variations, connotative differences and origin of words.

\footnotetext{
${ }^{2}$ The reader is encouraged to go to the appendix which is helpful to identify the phonemic transcription.
} 
Many synonymous words belong to different varieties of the same language. This paper attempts to investigate synonymy within sub-dialects of Jordanian Arabic, which is rich in synonyms that differ in their dialectical associations. The following examples show synonymous words in Jordanian Arabic. As far as food items are concerned, it is possible to note an array of synonyms. Here we would say that SariiH, shaniiniyeh, liban meaning 'yogurt' have similar meaning, as they belong to Tafila Dialect, Falahi Dialect and Bani Hassan Dialect respectively. In most Jordanian colloquial dialects, teen is used to mean 'fig', whereas HamaaT is commonly used in Tafila Dialect.

Synonymy is expected to define the physical and ethical characteristics of people. In Bedouin Dialect, mazyuunah meaning ' a beautiful young woman' is synonymous with the word Hashmah in Bani Hassan Dialect. In Falahi Dialect, the word Halwah is also used to convey the same meaning. Not only is synonymy used to describe the beauty of women, but it is also to characterise people's social behaviour. In Bani Hassan Dialect, mshiyam meaning 'awfully bad-mannered' might alternate with khaasii in Bedouin Dialect and khaam in Falahi Dialect. It should be maintained that mshiyam, khaasii and khaam all indicate how inhospitable the intended person is, given the fact that hospitability is an important aspect of politeness and good social behaviour not only in Jordan's culture but also in Islam.

Synonymous verbs are also used in Jordanian sub-dialects. For instance, sharad meaning 'escaped' is mainly used by the people of Tafila, whereas $f a l$ is often used by the people of Bani Hassan tribe. In other sub-dialects, harab can be used. In addition, in Bani Hassan Dialect, lid meaning 'look' alternates with other words such as baHir in the dialect of the people living in the eastern part of the country and ?iTala9 in Urban dialect for those who are familiar with these dialects.

Taboo words are used in speaking and it is noted there are a set of synonyms in Jordanian Arabic. For example, taboo words in Bani Hassan Dialect are synonymous with words from other dialects. The same is true of Bedouin Dialect, which has taboo words different in form from other dialects. As the Jordanian community is Islam-oriented, this paper is likely to offend Jordan's religious and sexual sensibilities if it gives these synonyms in detail.

\subsection{The evaluative meaning of synonyms}

Even though many words in Jordanian Arabic have the same denotative meaning, the connotations connected to these words are not the same (i.e. they have positive, negative and neutral associations). As in other languages, it is very difficult to argue that there is perfect synonymy in Jordanian Arabic.

In many cases, the evaluative meaning of synonyms in Jordanian Arabic is not expected to be positive. This is more apparent in the recent or new coinages expressing the speaker's intent to criticise and ridicule people's social behaviour and character. On Jordanian university campuses, Jordanian students say that 'flaan rasab bil?imtiHaan' and 'flaan Tabbal bil?imtiHaan'. Even though both utterances mean ' $\mathrm{X}$ failed in the exam', the utterance that includes the synonym Tabbal is more critical than the former. Not only is the latter utterance referential, but it is also expressive (i.e. the students feel sorry about the failure of $\mathrm{X}$ in the exam and might ridicule him for being a stupid student). In Jordanian social settings, it is more critical to use the utterance 'shamasat flaan Gudaam flaan' than the utterance 'fadhaHt flaan Gudaam flaan' meaning 'I revealed everything about X in front of Y'. Even though both shamas and fadhaH have the same denotative meaning, 'reveal everything', the connotative meaning is different in the sense that the former is significantly meant to ridicule. In some Jordanian Arabic dialects, for example Bani Hassan Dialect, the word khatyaar meaning 'old man' alternates with the word shaayib. Nevertheless, the latter often involves the speaker's adverse judgements towards the addressee, as in 'haatha ashaayib najis' meaning 'That old man is very wicked'.

However, some words tend to be more positive than others. In normal everyday circumstances, the utterance 'flaan rajul Hashyim' shows a more positive attitude than the utterance 'flaan rajul mratab' meaning ' $\mathrm{X}$ is an extremely good man'. Although both utterances have the same denotative meaning, the word Hashyim 'extremely good' conveys the speaker's emotive attitude towards certain people; in contrast, the word mratab is more neutral than the former synonym (i.e. in most cases, it does not convey the connotative and emotional senses expressed by the word Hashyim).

\subsection{Origin of words}

Jordanian Arabic is very rich in synonyms from different foreign sources, especially from the English language. Tayyib and mashii are both synonymous with ?okeh, from English 'okay'. The same is true of Qahwah, which is synonymous with Kofiishob, originally from English 'coffee shop'. ?eibril, originally from English 'April', the fourth month of the year, is synonymous with shahar ?arba9ah. In addition, biznis, closely related to English 'business', alternates with its Jordanian Arabic equivalent shughul. keirv meaning 'a street curve' alternates with kourabah. The English-origin fiftiififtii alternates with 9anus. In addition, the loanword frish, which is originally from the English word 'Fresh', is synonymous with Taazah.

Jordanian Arabic is also rich in words of Turkish origin. This is manifested in the use of many Turkish-origin words in daily life activities. Many Turkish names of food items are commonly used in spoken and written modes; such food names are seen on storefronts in the linguistic landscape of Jordanian cities. For example, buuzah alternates with the English loanword ?aiskriim, from English 'ice-cream'. Furthermore, the Turkish loanword kaazouzah alternates with the lexeme Gazaziit bibsii meaning 'a Pepsi drinking glass'. Many Turkish military ranks are still used in speaking, as in the case of shaawiish meaning 'sergeant' alternating with ragiib. Many Turkish job titles are commonly used in Jordanian Arabic; for example, Toubarjii meaning 'builder' is a synonym of words such as mi9marjii and banaa. Moreover, the Turkish lexical borrowing bouya 'shoe polish' alternates with the word kiiwii. 
Jordanian Arabic uses many loanwords from French. For example, diluks, from French 'deluxe', which penetrated Jordanian Arabic through the English language, is a synonym of the lexeme minalaakhar. In addition, ribourtaaj, from French 'reportage', alternates with the word tagriir. These examples show that French loans might be incorporated into Jordanian Arabic to satisfy the cultural needs of the Jordanian community.

\section{Concluding remarks}

Many words in Jordanian Arabic should be seen as partially rather than totally synonymous. This has been explored through the analysis of apparently synonymous words in Jordanian Arabic. This study has shown that none of the synonyms examined can be called total synonyms. On the basis of the analysis of the results of the study, the synonyms in Jordanian Arabic differ in some aspects: dialectical variations, the speaker's emotive attitude and origin of words.

As discussed above, linguists have stressed the economy of language. This means the impossibility of finding words in a language having the same meaning. In Jordanian Arabic, many instances of synonymy reflect a duplication associated with Arabic and foreign resources. Even though most new coinages arise from Arabic, many words are coined based on foreign sources: English, Turkish, and French. In the last two decades, a wide range of words have been borrowed from English, as English is the language of technology, scientific advances, modernity, and communication with the outside world.

\section{References}

Al-Omari, S. \& Abu-Melhim, A. (2014). Synonymy in English and Arabic with reference to the Holy Qur'an: a contrastive study. Theory and Practice in Language Studies, 4(12), pp. 2619-2626.

Alomoush, O. \& Al Fagara, W. (2010). The adaptation of English loanwords into Jordanian Arabic. Journal of Language \& Literature, 2, pp. 27-39.

Alomoush, O. \& Matarneh, M. (2010). The spread of code-switches into Jordanian social settings. International Journal of Philosophy of Culture \& Axiology, 20(7), pp.223-233.

Constitution of the Hashemite Kingdom of Jordan. Available from URL http://www.kinghussein.gov.jo/constitution_jo.html (Accessed January 16, 2015).

Cruse, D. A. (1986). Lexical semantics. Cambridge: Cambridge University Press.

Cruse D. A. (2000). Meaning in language: an introduction to semantics and pragmatics. Oxford: Oxford University Press.

Elhassan, Sh. (2001). 9ILM Adalaaleh Asimanteekiyeh Walbraagmaateekiyeh Fii Alugheh Al9rabiyiyeh. Amman: Thought House.

Ferguson, C. (1959) 'Diglossia'. In: Giglioli, P. ed. Language and social context, Harmondsworth: Penguin, pp. $232-51$.

Fromkin, V. \& Rodman, R. (1993). An introduction to language (5th ed.). Fort Worth, TX: Harcourt Brace.

Llyas, A. I. (2014). 'Cohesive devices in the short suras of the Glorious Quran', Arab World English Journal, Special issue, pp.135-146.

Lobner, S. (2002). Understanding semantics. London: Hodder.

Lyons, J. (1969). Introduction to theoretical linguistics. Cambridge: Cambridge University Press.

Lyons, J. (1981a). Language meaning and context. Glasgow: Fontana.

Lyons, J. (1981b). Language and linguistics. Cambridge: Cambridge University Press.

Lyons, J. (1995). Linguistic semantics: an introduction. New York: Cambridge University Press.

Mel'cuk, I.A (2012). Semantics: from meaning to text. Amsterdam NLD: Benjamins.

Omar, A. M. (2000). 'Complete and near synonymy in the Holy Qur'an', Journal of Qur'anic Studies, 2(1), pp. 198-182.

Palmer, F.R. (1981). Semantics. Cambridge: Cambridge University Press.

Schulte, M. (2015). 'Polysemy and synonymy in derivational affixation a case study of the English suffixes -age and er', Morphology 25, pp. 371-390.

Appendix: Speech sounds in Jordanian Arabic and their description

\begin{tabular}{ll}
\hline Consonants and vowels & Description \\
\hline$?$ & Voiceless glottal stop \\
\hline $\mathrm{b}$ & Voiced bilabial stop \\
\hline $\mathrm{j}$ & Voiced palatal fricative \\
\hline $\mathrm{d}$ & Voiced dental stop \\
\hline $\mathrm{h}$ & Voiceless laryngeal fricative \\
\hline
\end{tabular}




\begin{tabular}{|c|c|}
\hline $\mathrm{W}$ & Labio-velar glide \\
\hline $\mathrm{x}$ & Voiced dental fricative \\
\hline $\mathrm{H}$ & Voiceless pharyngeal fricative \\
\hline $\mathrm{T}$ & Voiced dental stop \\
\hline $\mathrm{y} / \mathrm{ii}$ & Palatal glide \\
\hline $\mathrm{k}$ & Voiceless velar stop \\
\hline 1 & Alveolar palatal \\
\hline $\mathrm{m}$ & Bilabial nasal stop \\
\hline $\mathrm{s}$ & Alveolar nasal stop \\
\hline $\mathrm{s}$ & Voiceless dental fricative \\
\hline 9 & Voiced pharyngeal \\
\hline $\mathrm{f}$ & Voiceless labio-dental fricative \\
\hline $\mathrm{S}$ & Voiceless dento-alveloar fricative \\
\hline Q & Voiceless uvular plosive \\
\hline $\mathrm{r}$ & Alveolar flap \\
\hline sh & Voiceless palato-alveolar fricative \\
\hline $\mathrm{t}$ & Voiceless dental stop \\
\hline th & Voiceless dental fricative \\
\hline $\mathrm{kh}$ & Voiceless uvular fricative \\
\hline th & Voiced dental fricative \\
\hline $\mathrm{dh}$ & Voiced velarised alveolar stop \\
\hline $\mathrm{D}$ & Voiced velarised interdental fricative \\
\hline gh & Voiced velar fricative \\
\hline $\mathrm{i}$ & Short high front unrounded vowel \\
\hline ii & Long high front unrounded vowel \\
\hline a & Short low central unrounded vowel \\
\hline aa & Long low central unrounded vowel \\
\hline $\mathrm{u}$ & Short high back rounded vowel \\
\hline $\mathrm{uu}$ & Long high back rounded vowel \\
\hline o & Short mid-back rounded vowel \\
\hline
\end{tabular}

